\title{
A web-based information system for a regional public mental healthcare service network in Brazil
}

Vinicius Tohoru Yoshiura ${ }^{1,2^{*}}$, João Mazzoncini de Azevedo-Marques ${ }^{2,3}$, Magdalena Rzewuska ${ }^{4}$, André Luiz Teixeira Vinci ${ }^{2}$, Ariane Morassi Sasso ${ }^{2}$, Newton Shydeo Brandão Miyoshi ${ }^{2}$, Antonia Regina Ferreira Furegato ${ }^{5}$, Rui Pedro Charters Lopes Rijo ${ }^{6}$, Cristina Marta Del-Ben ${ }^{7}$ and Domingos Alves 2,3

\begin{abstract}
Background: Regional networking between services that provide mental health care in Brazil's decentralized public health system is challenging, partly due to the simultaneous existence of services managed by municipal and state authorities and a lack of efficient and transparent mechanisms for continuous and updated communication between them. Since 2011, the Ribeirao Preto Medical School and the XIII Regional Health Department of the Sao Paulo state, Brazil, have been developing and implementing a web-based information system to facilitate an integrated care throughout a public regional mental health care network.
\end{abstract}

Case presentation: After a profound on-site analysis, the structure of the network was identified and a web-based information system for psychiatric admissions and discharges was developed and implemented using a socio-technical approach. An information technology team liaised with mental health professionals, health-service managers, municipal and state health secretariats and judicial authorities. Primary care, specialized community services, general emergency and psychiatric wards services, that comprise the regional mental healthcare network, were identified and the system flow was delineated. The web-based system overcame the fragmentation of the healthcare system and addressed service specific needs, enabling: detailed patient information sharing; active coordination of the processes of psychiatric admissions and discharges; real-time monitoring; the patients' status reports; the evaluation of the performance of each service and the whole network. During a 2-year period of operation, it registered 137 services, 480 health care professionals and 4271 patients, with a mean number of 2835 accesses per month. To date the system is successfully operating and further expanding.

Conclusion: We have successfully developed and implemented an acceptable, useful and transparent web-based information system for a regional mental healthcare service network in a medium-income country with a decentralized public health system. Systematic collaboration between an information technology team and a wide range of stakeholders is essential for the system development and implementation.

Keywords: Health information systems, Mental health, Public health informatics, Health management, Health networks

\footnotetext{
${ }^{*}$ Correspondence: viniciusyoshiura@usp.br

${ }^{1}$ Interunit Bioengineering Postgraduate Program, University of São Paulo,

São Paulo, Brazil

Full list of author information is available at the end of the article
} 


\section{Background}

Brazil is a rapidly developing middle-income country with the world's fifth largest population. To meet specific regional healthcare needs for comprehensive, universal preventive and curative care of this large and diverse society, a unified and decentralized public healthcare system was created in Brazil in 1988 [1]. Since then there has been rapid scaling up of integrated care approaches to public healthcare provision [1]. However, a regional integration between services, including the mental healthcare system, is still limited and extremely challenging; mostly due to decentralization of health service structures and a complex private-public health care mix [1]. The development of the mental health services network began in the $80 \mathrm{~s}$ and accelerated in recent years, including the expansion of community services and the reduction of beds in psychiatric hospitals. This rapid scaling up of a community-based mental healthcare approach has led to an urgent need to develop new, feasible integration strategies for mental health services in Brazil [2,3]. Low and middle-income countries have successfully implemented web-based systems to integrate health services information, but not for mental health service networks [4].

Since the mid-90s, a gradual expansion of the mental health services network has occurred in the XIII Regional Health Department (XIII RHD) of the Sao Paulo State, including 26 municipalities with an overall population of approximately $1,400,000$ inhabitants. This expansion has involved local and regional community-based services, outpatient clinics, psychiatric hospital wards and psychiatric wards in the general hospital of the Ribeirao Preto Medical School of the University of Sao Paulo (RPMSUSP) $[5,6]$.

The regional health committee that comprises state and municipal health authorities, established a mental health advisory group [7], as permitted by the enactment of the Brazilian health law legislation on that matter. The committee is managed by the state government, municipalities and the RPMS-USP. Amongst its statuary activities are monthly meetings, with representatives of all public mental health services in the region during which participants propose standards for the operation of mental health services, including guidelines for the coordination between hospital and community-based care.

Since 2004, the demand for mental health care has progressively increased in the region of the XIII RHD, resulting in longer waiting time for treatment and increasing difficulties with coordination of care between the services $[5,6,8]$. A major underlying problem was a rapid updating of information about the exact structure of the system and its flow. Another fundamental problem was an absence of suitable health information system technology in healthcare services (e.g. computers with internet connectivity and updated web browsers), especially in small municipalities. Consequently, information sharing and access within the public mental health service network were inadequate, lacking information on psychiatric beds availability, situation of the request lists for hospitalization, referrals, appointments, follow-ups and management reports.

To facilitate integration of the information and processes of care, the regional state health authority, with the support from municipal health authorities and the mental health advisory group, proposed in 2011 the development of a computerized information system, tailored to the specific characteristic and needs of the regional mental health care services network $[9,10]$.

\section{Case presentation}

Following the request of regional health authorities, the Center of Information and Informatics in Health (Portuguese: "Centro de Informação e Informática em Saúde"- "CIIS") of RPMS-USP obtained funding from the Secretary of Health of Sao Paulo state to develop the computerized system for the regional public mental health care service network. A socio-technical approach was used, in which the potential users actively collaborated with technical developers during the development and implementation of the computerized information system, through strategies, such as [11, 12]: (a) frequent meetings with different groups of stakeholders, both separately and jointly, formally invited by the regional mental health advisory group; (b) detailed discussions of requirements to be addressed by the new system, according to the needs and values of each group of stakeholders; (c) a definition of an operation model of the computerized system that meets a set of requirements of each group of stakeholders and implies the minimum required change in the working process of each type of service; (d) a definition of the minimum human resources needed (including system user training) and the minimum equipment needed for the adequate functioning of the system, considering the reality of the different services (including the capacity of municipal and regional managers to make new investments) and (e) a definition of a feasible process of maintenance and improvement of the computerized system considering the needs, values and resources of each group of stakeholders and the different services.

The mental health advisory group and the CIIS team made the initial decision to involve a wide range of professionals from different services and not involve patients and/or their family members, given that only the former group will be the system users. The invited health service managers, health professionals, municipal and regional health secretariats and judicial authorities decided to initially implement a web-based system to improve 
the process of requests and authorizations for hospital admissions and discharges within the network, hosted in a server of the RPMS-USP and using only free, nonprofit software and web address' service. To achieve this goal, the system should facilitate the matching of each patient with the most appropriate hospital or community-based service available by detailed sharing of patient information between services. It was decided by the committee that the system would aim to provide transparent and real-time information through performance indicators for each service and the whole network, such as number of requests for hospitalization, waiting time for hospitalization, types of hospitalization and discharges processed, length of stay, number of occupied beds and psychiatric diagnosis of admitted patients.

The technical developers and stakeholders established that there were computers with internet access and human resources available in each health care service that could be incorporated in the new system, if an initial training and ongoing technical support by the RPMSUSP were provided. The following software was adopted: MySQL Database Management System and NetBeans platform framework. Web technologies such as hypertext pre-processor (PHP), hypertext markup language (HTML), cascading style sheets (CSS) and javascript were used.

Following the end of the developmental phase, the involved stakeholders and administrative staff of the health care services completed training sessions. A system's pilot test was carried out in August-October 2012 and subsequently it entered in the operational stage. Moreover, appointed members of the regional mental health advisory group and the information technology team formed a monitoring group to perform monthly evaluations and improvements of the system. They have decided that the system's capacity to achieve the aims for which it had been created would be assessed by the total number of its users, the total number of system's access and through feedback of the system users (including verbal descriptions and a system survey).

A series of discussions with the potential service users led to a consensus on the exact structure and flow of the public mental healthcare service network (MHSN) in the region of XIII RHD (Fig. 1). Whilst the stakeholders recognized serious difficulties in sharing information between services within the same municipality or services managed by the state, they concluded that each service follow the federal standards of functioning.

The red arrows represent possible ways of patient referrals encompassed in the developed system, including judicial requests, whereas the black arrows represent possible ways of patient referrals that have not yet been incorporated in the system. Additionally, while the orange boxes portray regional services, which attend patients from all municipalities of the XIII RHD, the blue boxes portray municipal services that only attend local population.

The MHSN consists of mental health specialized services network (MHSSN), an emergency care network $(\mathrm{ECN})$ and primary health care services. The MHSSN is divided into: a hospital service network (acute and longstay wards in psychiatric hospitals and acute psychiatric wards of the General Hospital of University of Sao Paulo-GHU) and an outpatient service network (community mental health centers with or without overnight stay; mental health ambulatories, including those in the GHU; therapeutic communities for alcohol and drug users and long-stay residential services). The ECN consists of: an emergency hospital service network (general hospital emergency units and a psychiatric emergency unit of the GHU) and an emergency outpatient service network (emergency ambulatories units with or without overnight stay).

The developed web-based system was entitled 'Sistema de Informação em Saúde Mental do XIII Departamento Regional de Saúde do Estado de São Paulo' ('SISAM13'; English: 'Mental Health Information System of the XIII RHD') [10]. Firstly, it allows: registering, searching and updating information for all patients (both personal and clinical data, including appointments, follow ups, requests for hospital admissions, hospital admissions and referrals); and management of reports for each service and the network as a whole. Secondly, it enables monitoring in real time with transparency of the waiting lists for hospital admissions and the availability of psychiatric beds. Finally, the system allows users to provide feedback, suggestions and request help directly from the information technology team. Table 1 shows the SISAM13 information fields (patient socio-demographic information, service administrative information and patient medical history), completed using a list of possible and free response answers.

From November 2012 to October 2014, the system recorded 4271 patients, 480 professionals and 137 services. As shown in Fig. 2, a mean number of 2835 system accesses per month (range of 2172 to 3204) occurred and the smallest number was counted in June 2014, which is probably related to the modification of the initial address of the system (which became a paid service in June 2014). In addition, the system contains information on requests for hospitalizations and hospitalizations performed by each service. For example, during the study period, the SISAM-13 registered: 2391 requests and 1437 hospitalizations for the psychiatric hospital of Ribeirao Preto; 1732 requests and 732 hospitalizations for the psychiatric emergency service; and 541 requests and 419 


\section{Mental Health Specialized Services Network}

Emergency Care

Network
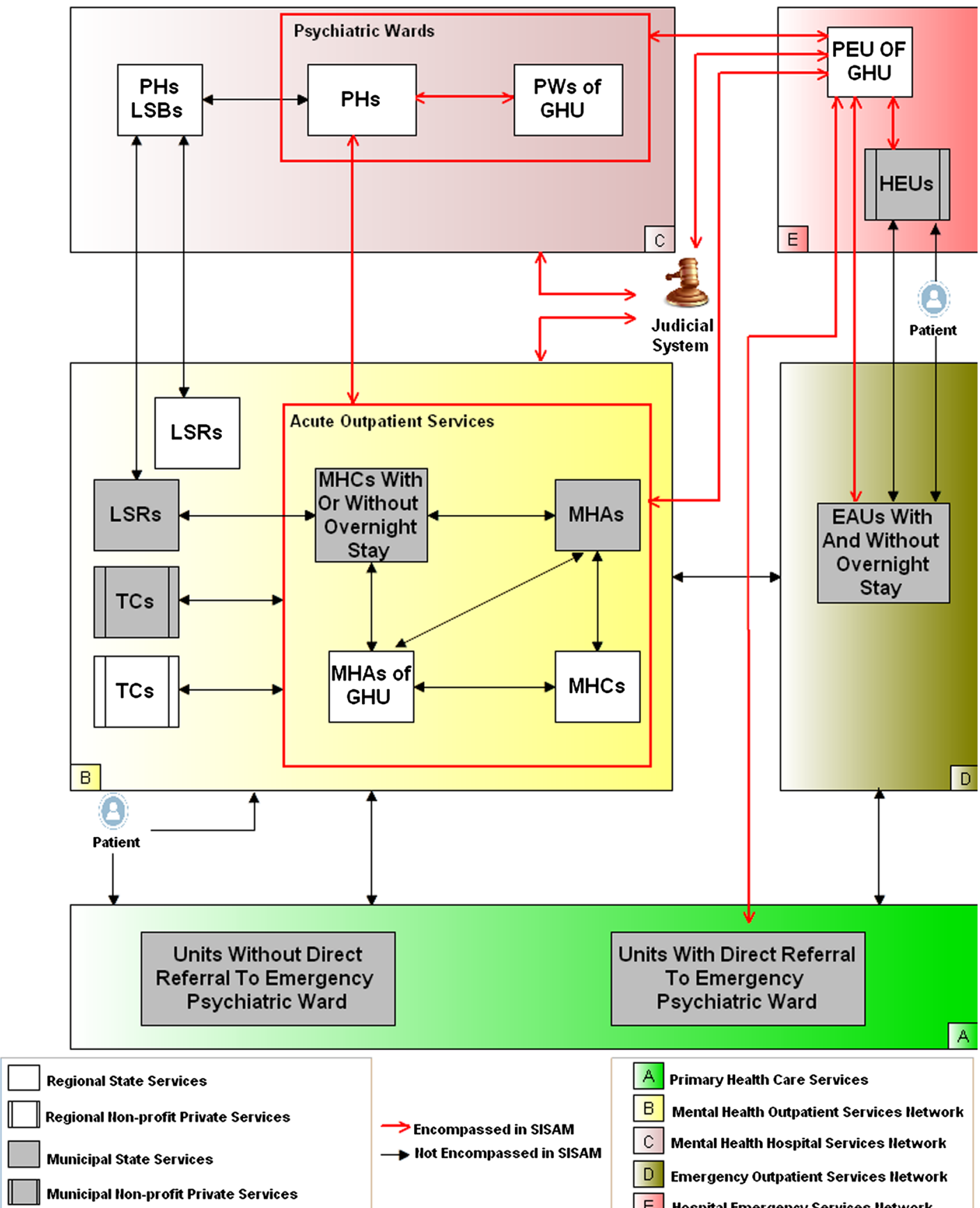

\section{Subittles}

$\mathrm{PH}$ - Psychiatric Hospitals LSB - Long Stay Beds

PW - Psychiatric Wards $\rightarrow$ Encompassed in SISAM

$\rightarrow$ Hot Encompassed in SISAM

Fig. 1 Structure and flow of the mental healthcare service network of the XIII Regional Health Department. EAUs emergency ambulatory units, HEUs general hospital emergency units, LSRs long stay residential services, MHAs mental health ambulatories, MHAs of GHU Mental Health Ambulatories of General Hospital of University of Sao Paulo, MHCs Mental Health Community Centers, PEU of GHU Psychiatric Emergency Unit of General Hospital of University of Sao Paulo, PHs Psychiatric Hospitals, PHs LSBs Psychiatric Hospitals Long Stay Beds, PWs of GHU Psychiatric Wards of General Hospital of University of Sao Paulo, TCS therapeutic communities 


\section{Table 1 The SISAM-13 information fields}

\begin{tabular}{|c|c|}
\hline Information type & Details \\
\hline \multicolumn{2}{|l|}{ Patient sociodemographic information } \\
\hline \multicolumn{2}{|l|}{ Patient information } \\
\hline \multicolumn{2}{|l|}{ Patient's name } \\
\hline \multicolumn{2}{|l|}{ Mother's name } \\
\hline \multicolumn{2}{|l|}{ Date of birth } \\
\hline National identification & Identity card number \\
\hline Taxpayer registry identification & Individual taxpayer registry identification number \\
\hline Public healthcare identification & National health card number \\
\hline Gender & Male, female, transsexual \\
\hline Address & Street, district, state, city, zip code \\
\hline Telephone & Residential, mobile phone, work \\
\hline Race/ethnicity/skin colour & Black, white, yellow, indigenous, brown \\
\hline Marital status & Married, single, divorced, widow/widower \\
\hline Living arrangements & $\begin{array}{l}\text { Living with a partner, parents, children, other family members, acquaintances/friends, } \\
\text { alone, other }\end{array}$ \\
\hline \multicolumn{2}{|l|}{ Occupation } \\
\hline \multicolumn{2}{|c|}{ Spouse, emergency contact, next of kin or carer's information } \\
\hline \multicolumn{2}{|c|}{ Name } \\
\hline Relationship & Spouse, brother/sister, father/mother, other \\
\hline \multicolumn{2}{|l|}{ E-mail } \\
\hline \multicolumn{2}{|l|}{ Service administrative information } \\
\hline \multicolumn{2}{|l|}{ User's information } \\
\hline \multicolumn{2}{|l|}{ Name } \\
\hline Gender & Male, female, transsexual \\
\hline Type of professional council & $\begin{array}{l}\text { Regional Council of Medicine, nursing, psychology, social service, physiotherapy, } \\
\text { nutritionist, lawyers, other }\end{array}$ \\
\hline \multicolumn{2}{|l|}{ Professional registration number } \\
\hline Issuing authority & \\
\hline \multicolumn{2}{|l|}{ E-mail } \\
\hline Telephone & Residential, mobile phone, work \\
\hline \multicolumn{2}{|l|}{ System registration date } \\
\hline Login & Username, password \\
\hline \multicolumn{2}{|l|}{ Current place(s) of work } \\
\hline Type of the system access permission & $\begin{array}{l}\text { Psychiatrist, physician, resident physician, others health professional, shared use within } \\
\text { the service, service manager, service secretary, system administrator, judge }\end{array}$ \\
\hline \multicolumn{2}{|l|}{ Service's information } \\
\hline Service & Name, Address, State, Zip Code, City \\
\hline Type of health service & $\begin{array}{l}\text { Primary health care, mental health outpatient, mental health hospital, emergency } \\
\text { outpatient, emergency hospital service }\end{array}$ \\
\hline Regional Health Department & Name \\
\hline Contact & Email, telephone \\
\hline \multicolumn{2}{|l|}{ Number of beds } \\
\hline Type of bed & Male, female, both \\
\hline \multicolumn{2}{|l|}{ Hospital ward } \\
\hline \multicolumn{2}{|l|}{ Patient's medical history information } \\
\hline \multicolumn{2}{|l|}{ Outpatient care } \\
\hline Service & Name \\
\hline \multicolumn{2}{|l|}{ Referral date } \\
\hline Type of referral & $\begin{array}{l}\text { Scheduled new case, scheduled return, counter-reference, emergency/clinical inter- } \\
\text { currence, workshop }\end{array}$ \\
\hline
\end{tabular}




\section{Table 1 continued}

\begin{tabular}{|c|c|}
\hline Information type & Details \\
\hline Professional(s) involved in the patient's care & $\begin{array}{l}\text { Physician, social worker, nurse, nursing technician, dentist, physiotherapist, psy- } \\
\text { chologist, physical educator, speech therapist, pharmacist, occupational therapist, } \\
\text { nutritionist, other }\end{array}$ \\
\hline Type(s) of care & Individual, group, family care, home visit, workshops, psychosocial rehabilitation, other \\
\hline \multicolumn{2}{|l|}{ Reference and counter-reference } \\
\hline Type & Reference/counter-reference \\
\hline \multicolumn{2}{|l|}{ Date } \\
\hline \multicolumn{2}{|l|}{ Responsible healthcare professional } \\
\hline \multicolumn{2}{|l|}{ Service/municipality of origin } \\
\hline \multicolumn{2}{|l|}{ Destination service/municipality } \\
\hline \multicolumn{2}{|l|}{ Motive } \\
\hline \multicolumn{2}{|l|}{ Requests for hospitalization } \\
\hline \multicolumn{2}{|l|}{ Requesting health professional } \\
\hline \multicolumn{2}{|l|}{ Service/municipality of origin } \\
\hline \multicolumn{2}{|l|}{ Hospital/municipality service } \\
\hline Overnight stay at the service of origin & Yes/no \\
\hline \multicolumn{2}{|l|}{ Message history between health professionals } \\
\hline \multicolumn{2}{|l|}{ Request for hospitalization history } \\
\hline Name of the judge & Judiciary request for information \\
\hline District Attorney & Judiciary request for information \\
\hline Applicant & Judiciary request for information \\
\hline Judicial district & Judiciary request for information \\
\hline Case number & Judiciary request for information \\
\hline Number of the judicial process & Judiciary request for information \\
\hline Judicial order number & Judiciary request for information \\
\hline Compulsory indication & Treatment for chemical dependency, treatment for mental disorder, other \\
\hline Judicial injunction & Judiciary request for information \\
\hline \multicolumn{2}{|l|}{ Hospitalization } \\
\hline \multicolumn{2}{|l|}{ Hospital/municipality } \\
\hline \multicolumn{2}{|l|}{ Medical record number } \\
\hline \multicolumn{2}{|l|}{ Bed number } \\
\hline \multicolumn{2}{|l|}{ Responsible healthcare professional } \\
\hline \multicolumn{2}{|l|}{ Hospitalization date } \\
\hline Type of hospitalization & $\begin{array}{l}\text { Determined by a judicial authority, determined by a psychiatrist without patient's } \\
\text { consent, determined by a psychiatrist with patient's consent }\end{array}$ \\
\hline Service of origin & Name, Municipality \\
\hline \multicolumn{2}{|l|}{ Requesting health professional } \\
\hline \multicolumn{2}{|l|}{ Date of discharge } \\
\hline Type of discharge & $\begin{array}{l}\text { By a psychiatrist, at the request of the patient or his/her family, administrative (ex. due } \\
\text { to patient's misbehaviour), escape, death, inter-hospital transfer in the network or } \\
\text { transfer to other medical specialities }\end{array}$ \\
\hline \multicolumn{2}{|c|}{ Name of the professional responsible for discharge } \\
\hline \multicolumn{2}{|c|}{ Inter-hospital transfer destiny } \\
\hline \multicolumn{2}{|l|}{ Motive for inter-hospital transfer } \\
\hline \multicolumn{2}{|l|}{ Patient clinical information } \\
\hline \multicolumn{2}{|l|}{ Outpatient care } \\
\hline Primary diagnosis & According to the ICD-10 \\
\hline Other diagnosis & According to the ICD-10 \\
\hline Summary & Summary of the patient's consultation/activity/workshop \\
\hline
\end{tabular}


Table 1 continued

\section{Information type}

Request for hospitalization

Motive for request

Hypertension

Diabetes

Infectious disease

Trauma

Respiratory problems

Sequelae of cerebrovascular accident

Epilepsy

Others comorbidities

Medical exams

Medication

Initial diagnostic hypothesis

Other diagnostic hypothesis

Treatment modality

Hospitalization

Motive for hospitalization

Primary diagnosis

Other diagnosis

Discharge primary diagnosis

Discharge other diagnosis

Comorbidities

Initial medication

Discharge medication

Medical exam results

Summary of clinical history

Treatment

\section{Details}

Abstinence from use of psychoactive substances, psychomotor agitation, self-harm/ hetero-aggressive behaviour, delirium tremens, suicidal ideation, psychoactive substance intoxication, judicial request, first psychiatric outbreak, severe depressive illness, maniac outbreak, other

Yes, no, no information

Yes, no, no information

Yes, no, no information

Yes, no, no information

Yes, no, no information

Yes, no, no information

Yes, no, no information

Name

According to the ICD-10

According to the ICD-10

Intensive, non-intensive, semi-intensive

Abstinence from use of psychoactive substances, psychomotor agitation, self-harm/ hetero-aggressive behaviour, delirium tremens, suicidal ideation, psychoactive substance intoxication, judicial request, first psychiatric outbreak, severe depressive illness, maniac outbreak, other

According to the ICD-10

According to the ICD-10

According to the ICD-10

According to the ICD-10

ICD-10 the International Statistical Classification of diseases and related health problems, Version 10

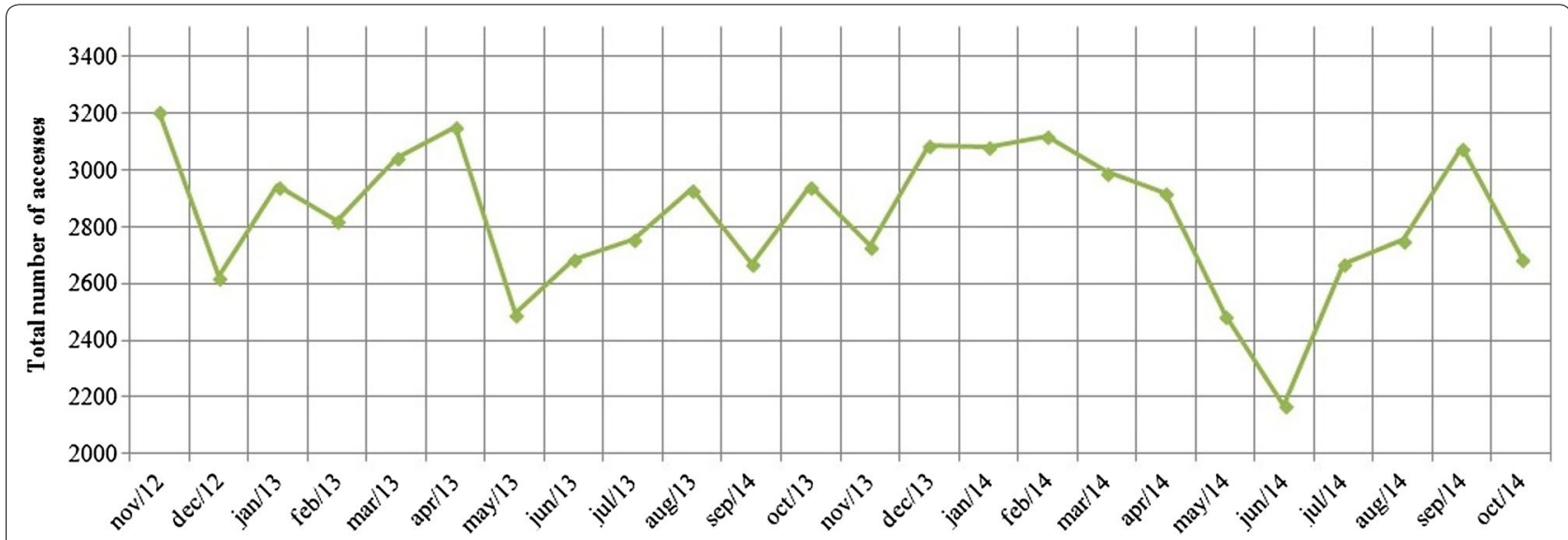

Fig. 2 Total number of accesses per month to the 'Mental Health Information System of the XIII RHD' 
hospitalizations for the psychiatric ward in the general hospital, data that can be divided in other types of information that can be provided.

During that period of 2 years, the monitoring group found through conversations with the stakeholders that the majority of users considered that the objectives of the web-based system had been met. Information sharing has become easier and faster, facilitating discussions and decisions about the type of care each patient needed. Municipalities that lacked any information system now use the SISAM-13 to assess information on referrals to hospitalization services [10]. The system generates hospital indicators that are important for decision making processes of the advisory group whose goal is to upgrade the existing services and create new ones. The main difficulties encountered during the system development and implementation included the conciliation of different interests from the stakeholders and the resistance of some health care professionals to use health information systems due to unfamiliarity and reservations about its security.

From September 2013 to April 2014, a survey was made available in the main menu of the system in order to verify the feasibility of the system. Twenty-six people participated in the survey: $80.76 \%$ were satisfied with the improvement of their working environment; $69.23 \%$ were satisfied with the navigability of the system; $84.61 \%$ were satisfied that the system conforms to their requirements; $80.76 \%$ were satisfied with the accuracy and consistency of the information; and $80.76 \%$ were satisfied with the improvement of patient care. The questionnaire included an open-ended question requesting that users add any comments they might have regarding the SISAM-13. The criticisms made to the system were related to the following topics: (a) difficulties in access or maintaining access to the system through the internet; (b) difficulties for the same professional to access the information about hospitalization requests from different patients within the SISAM-13 (the user had to return to the home page to restart the entire process for each patient); (c) a lack of an intelligent search engine by patient name, with the exact match option only being available; (d) a lack of "report" option with graphical displays; (e) a lack of possibility to make a new request for hospitalization without having to cancel the previous request and (f) a lack of pop-up notifications about received communication. The monitoring group used this feedback to continue improving the system.

Semi-structured interviews were conducted in 2016 as part of an ongoing qualitative study aiming to understand the daily practice of health community services in care of primary care patients with coexisting chronic physical health problems and depression or anxiety (including the use of computerized information systems) [13]. To date sixty primary care and mental health professionals were interviewed. Thematic analysis of the data suggests that the SISAM-13 facilitates psychiatric hospitalization by both general practitioners and community mental health specialists:

"I can forward (for hospitalization) [...] I put [a patient] in the system, which is the SISAM, a patient with psychotic outbreak, suicide attempt, self-harm. There's a place I can do that and see where he has gone". (General Practitioner)

"The SISAM is working well. We are using it more to see or to request hospitalizations and all patients who are now going through consultations I register with the SISAM". (Community mental health service manager 1)

The SISAM-13 also plays an important role in information sharing and subsequently enhancing continuity of care:

"The SISAM that also makes it easier for us, we can see if there is a patient from the outpatient clinic that is waiting for a vacancy and talk about that patient or family member looked after by us, finally we can make this exchange [of information]. "(Community mental health service manager 2)

"A patient escaped from a [psychiatric] hospital and he came here [...] I knew that I had requested his hospitalization by the SISAM in this psychiatric hospital, [...] she should have come with a [discharge] conuter-reference. He came without it. This is how we found out [that he escaped]" (Community mental health service manager 3)

A Ph.D. project will be conducted in 2017 [14] involving semi-structured interviews and focus groups, with various users of the SISAM-13 on their experiences with the system a during 5 -year period of its implementation.

Hearing experiences and addressing needs of a wide range of stakeholders in the process of development and implementation is challenging [15], but it was necessary to achieve this first Brazilian web-based system that meets specific service needs, integrate public mental health care service information and is currently being used in daily clinical practice. Therefore, it is important to understand and match different drives and interests of the stakeholders [16]. While health care professionals are interested in the system's capacity to ease the access to detailed patient information necessary for clinical decision making and the process of admission and discharge, managers and health authorities are driven by 
the system's capacity to inform allocation of health care resources.

The large numbers of actions performed by the users of the SISAM-13 and the positive feedback received confirmed its acceptability, feasibility and utility [9-12]. This enhanced networking between services facilitates an integrated regional mental health care and can be expected to make an important contribution to the improvement of the quality of patient care.

\section{Conclusion}

We have explored the local context, and specifically we delineated the exact structure of the mental healthcare system and the existing legal mechanisms of partnerships. As a result, to the best of our knowledge we provide the first description of exact structures and flow of the regional and local mental health care system network in the region of the XIII RHD that may serve as a guide for understanding healthcare system in other parts of Brazil. Moreover, in the process of the system development and implementation, we have received a great deal of support from municipal and state health authorities through regional health committees and advisory groups, which were pivotal to both acquisition of the required technology and the application of the SISAM13 in daily clinical practice $[15,17]$.

The main difficulties encountered during the implementation and development of the SISAM-13 were: (a) to harmonize both the demands of clinicians involved in direct patient care and the demands of managers of services and service networks; (b) ensure adequate access to the internet in all services; (c) guarantee at least one computer permanently connected to the internet in each service to allow the use of the system; (d) ensure a continuous and active user collaboration to monitor and improve the system through various strategies (monitoring group, survey and periodic training); e) ensure the availability of a team of computer technicians capable of developing the software.

The main current limitation of the SISAM-13 is that it is mostly used only to manage the interface between hospital and community services (i.e. hospitalizations and discharges). Other functions that are available through the system-such as record-keeping of an outpatient clinic appointment-are underused.

The CIIS has received additional funding from the Secretary of Health of Sao Paulo state, for further maintenance, improvement and expansion of the scope of the SISAM13. The system has been presented to managers of regional health departments of Sao Paulo state adjacent to XIII RHD, who have requested support for the system implementation and this request will be presented to the State Health Secretariat, along with detailed request for additional resources needed for expansion. To implement the system in other regions of Brazil the following minimum requirements need to be met: (a) availability of stakeholders willing to participate in meetings aiming for the system adaptation/implementation; (b) provision of the minimum human resources and equipment and (c) provision of adequately trained and funded system maintenance staff. The system will be further evaluated and improved by encouraging more users to complete feedback surveys and by conducting a qualitative research project. To achieve a more complete description of the network operation through health indicators, we developed an adaptation of the mental health matrix model [14, 18], for use as a conceptual framework to guide the development of a basic electronic health record that allows specific adaptations for every type of service $[10-12,17,19]$.

\section{Abbreviations}

XIII RHD: The Regional Health Department; CSS: cascading style sheets; ECN: the emergency care network; GHU: The General Hospital of University of Sao Paulo; HTML: hypertext markup language; ICD-10: The International Statistical Classification of Diseases and Related Health Problems; MHSN: the public mental healthcare service network; MHSSN: the mental health specialized services network; PHP: hypertext pre processor; RPMS-USP: The Ribeirao Preto Medical School of the University of Sao Paulo; SD: standard deviation; 'SISAM 13': Mental Health Information System of the XIII Regional Health Department.

\section{Authors' contributions}

VTY, DA, conceptualized the study; VTY, ALTV, AMS, NSBM, developed, implemented and evaluated the web-based information system and conducted data analyses; MR, JMAM; developed and conducted semi-structured interviews with healthcare professionals from community health services (including primary care and mental health services) about their daily practices of care for patients with coexisting chronic physical health problems and depression or anxiety; JMAM, DA supervised the system development, and implementation; VTY, drafted the first manuscript; JMAM, DA, MR, ALTV, AMS, NSBM, ARFF, RPCLR, CMDB, supervised data analyses, interpreted the results and critically reviewed the manuscript. All authors had the final approval of the article. All authors read and approved the final manuscript.

\section{Author details}

${ }^{1}$ Interunit Bioengineering Postgraduate Program, University of São Paulo, São Paulo, Brazil. ${ }^{2}$ Center of Information and Informatics in Health, Ribeirao Preto Medical School, University of São Paulo, São Paulo, Brazil. ${ }^{3}$ Department of Social Medicine, Ribeirao Preto Medical School, University of São Paulo, São Paulo, Brazil. ${ }^{4}$ Community Health Postgraduate Program, Ribeirao Preto Medical School, University of São Paulo, São Paulo, Brazil. ${ }^{5}$ Department of Psychiatry and Human Sciences, Ribeirao Preto College of Nursing, University of São Paulo, São Paulo, Brazil. ${ }^{6}$ School of Technology and Management, Polytechnic Institute of Leiria, Leiria, Portugal. ${ }^{7}$ Department of Neuroscience and Behaviour Science, Ribeirao Preto Medical School, University of São Paulo, São Paulo, Brazil.

\section{Acknowledgements}

We would like to thank all the participating representatives of public mental health services for their invaluable contribution to this system development and implementation and the XIII Regional Health Department of Sao Paulo state for their support.

Competing interests

The authors declare that they have no competing interests. 


\section{Availability of data and materials}

The datasets generated and/or analyzed by the current study is not available in the public domain, due to the data security and confidentiality reasons.

\section{Ethics approval and consent to participate}

This study was approved by the Ethics Committee of the Clinics Hospital Ribeirao Preto Medical School, University of Sao Paulo and the informed consent was not required, given the data was regarded not confidential, more specifically pseudo-anonymised (i.e. individual records could be identified by authorised personnel). The semi-structured interviews with healthcare professionals from community health services (including primary care and mental health services) on daily practice of care for patients with coexisting chronic physical health problems and depression or anxiety was approved by the Ethics Committee of the Clinics Hospital, Ribeirao Preto Medical School, University of Sao Paulo [Approval number: 48183515.9.0000.5440] and the informed consent was obtained from all participants using a written consent form.

\section{Funding}

This study was funded by the 'Conselho Nacional de Desenvolvimento Científico e Tecnológico' (CNPq) and 'Coordenação de Aperfeiçoamento de Pessoal de Nível Superior' (CAPES)—Science Without Borders Programme.

Received: 15 November 2016 Accepted: 28 December 2016

Published online: 03 January 2017

\section{References}

1. Paim J, Travassos C, Almeida C, Bahia L, Macinko J. The Brazilian health system: history, advances, and challenges. Lancet. 2011;377:1778-97.

2. Mateus MD, Mari JJ, Delgado PG, Almeida-Filho N, Barrett T, et al. The mental health system in Brazil: policies and future challenges. Int J Ment Health Syst. 2008:2:12.

3. Gregorio G, Tomlinson M, Gerolin J, Kieling C, Moreira HC, et al. Setting priorities for mental health research in Brazil. Rev Bras Psiquiatr. 2012;34:434-9.

4. Piette JD, Lun KC, Moura LA Jr, Fraser HS, Mechael PN, et al. Impacts of e-health on the outcomes of care in low- and middle-income countries: where do we go from here? Bull World Health Organ. 2012;90:365-72.

5. Barros RE, Marques JM, Carlotti IP, Zuardi AW, Del-Ben CM. Short admission in an emergency psychiatry unit can prevent prolonged lengths of stay in a psychiatric institution. Rev Bras Psiquiatr. 2010;32:145-51.
6. de Castro SA, Furegato AR, Santos JL. Sociodemographic and clinical characteristics of psychiatric re-hospitalizations. Rev Lat Am Enfermagem. 2010;18:800-8.

7. Victora CG, Barreto ML, do Carmo LM, Monteiro CA, Schmidt Ml, et al. Health conditions and health-policy innovations in Brazil the way forward. Lancet. 2011;377:2042-53.

8. Garla CC, Furegato ARF, Santos JLF. Professionals from mental health services: profile, practices and opinions on policies. Braz J Ment Health. 2010;2:74-93.

9. World Health Organization. Mental health information systems. Mental Health Policy and Service Guidance Package. Geneva: WHO; 2005.

10. Yoshiura VT. Development and deployment of a web based system for monitoring the mental health network [dissertation]. Sao Carlos: University of Sao Paulo; 2015.

11. Klein L. What do we actually mean by'sociotechnical'? On values, boundaries and the problems of language. Appl Ergon. 2014;45:137-42.

12. Eason K. Afterword: the past, present and future of sociotechnical systems theory. Appl Ergon. 2014:45:213-20.

13. de Azevedo-Marques JM, Rzewuska M, Santos JLF, Franco LJ, Zanetti ML, Coxon D, Zanetti ACG. Collaborative (integrated) care model for comorbid mental and physical health problems in Brazilian primary care. University of Sao Paulo. 2016. https://www.researchgate.net/project/ Desenvolvimento-de-modelos-de-apoio-matricial-para-melhorar-oacesso-e-a-qualidade-do-cuidado-de-pacientes-com-doencas-cronicasnao-transmissiveis-e-transtornos-ansiosos-e-ou-depressivos-na-atencaopr. Accessed 23 Dec. 2016.

14. Vinci ALT, Rijo RPCL, de Azevedo-Marques JM, Alves D. Proposal of an evaluation model for mental health care networks using information technologies for its management. Procedia Comput Sci. 2016;100:826-31.

15. Ludwick DA, Doucette J. Adopting electronic medical records in primary care: lessons learned from health information systems implementation experience in seven countries. Int J Med Inform. 2009;78:22-31.

16. Reddy M, Pratt W, Dourish P, Shabot MM. Sociotechnical requirements analysis for clinical systems. Methods Inf Med. 2003:42:437-44.

17. Cresswell K, Sheikh A. Organizational issues in the implementation and adoption of health information technology innovations: an interpretative review. Int J Med Inform. 2013;82:e73-86.

18. Tansella M, Thornicroft G. A conceptual framework for mental health services: the matrix model. Psychol Med. 1998;28:503-8.

19. Fraser HS, Biondich P, Moodley D, Choi S, Mamlin BW, et al. Implementing electronic medical record systems in developing countries. Inform Prim Care. 2005;13:83-95.

\section{Submit your next manuscript to BioMed Central and we will help you at every step:}

- We accept pre-submission inquiries

- Our selector tool helps you to find the most relevant journal

- We provide round the clock customer support

- Convenient online submission

- Thorough peer review

- Inclusion in PubMed and all major indexing services

- Maximum visibility for your research

Submit your manuscript at www.biomedcentral com/submit
Ciomed Central 